\title{
The Eight International Congress of the Croatian Society of Nuclear Medicine second announcement
}

\section{Dear Colleagues,}

It is my great pleasure to invite you to the Eight International Congress of the Croatian Society of Nuclear Medicine, May 09-12, 2014, which will take place in beautiful Šibenik — a historic town, located in central Dalmatia.

This is a very special occasion since 2014 we are celebrating $20^{\text {th }}$ anniversary of our first congress which took place in Zagreb 1994.

Our next congress will be the perfect opportunity to meet many of the world experts (about 20 invited lecturers) and to present your own achievements in the form of oral or poster presentations.

We are particularly glad to announce the $10^{\text {th }}$ Alpe-Adria Nuclear Medicine Symposium organized by the Austrian, Italian, Slovenian and Croatian Nuclear Medicine Societies which will be held on the same venue, on Sunday, May 11. The main topics of the symposium will be Hypothyroidism and Infection/Inflammation imaging.

Simultaneously with the main program, the Annual Meeting of the Croatian Society of Nuclear Medicine Technologists will be held on May 10-12, 2014.

Don't miss the opportunity to explore Šibenik and several national parks in the neighborhood. Joining our social events you will have a chance to meet your colleagues in person and discuss with them the most interesting topics of nuclear medicine.

Croatia is one of the most beautiful countries in Europe and we shall do our best to offer you a very pleasant stay and make you feel at home while being with us.

The most relevant information about the congress you'll find on our web-site http://public.carnet.hr/nuclmedzg-rebro/.

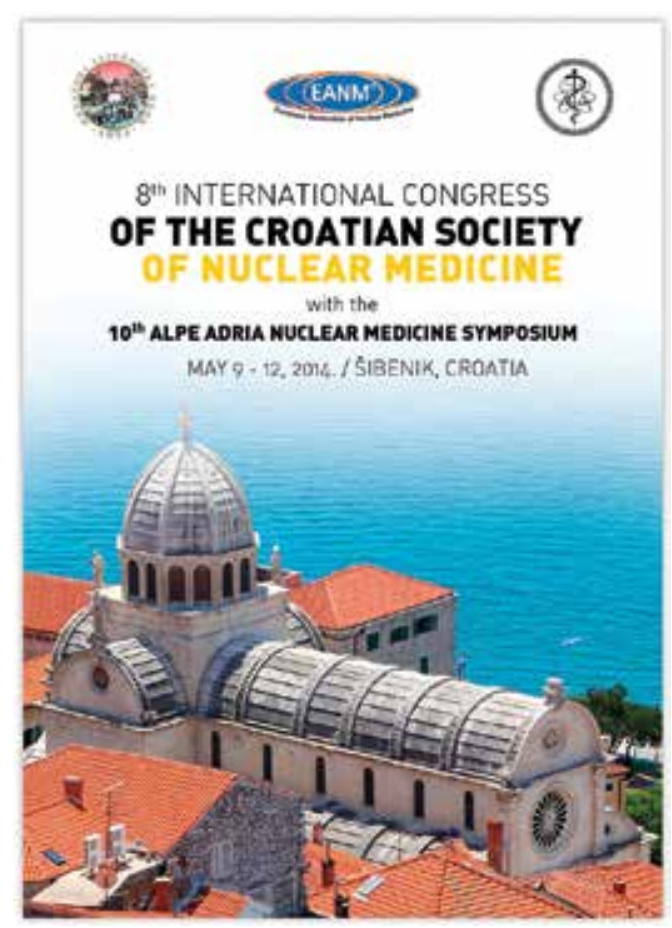

The final program will be available in March 2014.

We cordially invite you and look forward to seeing you in Šibenik in May 2014! Congress President 